$\xi=-1$

\title{
Characterization of Brass/Steel Plates Joined by Friction Stir Welding
}

\author{
Mariyappan.K ${ }^{1 *}$, Praveen $\mathrm{K}^{2}$, Suresh Kumar. $\mathrm{S}^{3^{*}}$, Kadambanathan.K ${ }^{4}$, Rajamanickam. $\mathrm{S}^{5}$, Vignesh.R ${ }^{6}$ \\ ${ }^{1,4,5,6}$ Department of Mechanical Engineering, Vel Tech High Tech Dr.Rangarajan Dr.Sakunthala Engineering College, \\ Chennai - 600062, India \\ ${ }^{2}$ Department of Mechanical Engineering, Sri Muthukumaran Institute of Technology, Chennai - 600069, India \\ ${ }^{3}$ Department of Mechanical Engineering, Panimalar Polytechnic College, Chennai - 600029, India \\ *Corresponding authorE-mail: jkmari143@gmail.com,sandysureesh@gmail.com
}

\begin{abstract}
The aim of this study is to show the feasibility for butt joining dissimilar brass to austenitic stainless steel plates by Friction Stir Welding. In this study, the limited FSW parameters were employed. Metallurgical characterization like Scanning Electron Microscopy and Mechanical characterization like tensile test, Micro hardness is done to investigate the joint performance and the weld zone of dissimilar brass/steel joints. The tensile strength and micro hardness values are $20 \mathrm{MPa}, 122 \mathrm{MPa}$ and $157 \mathrm{MPa}$ and $175 \mathrm{Hv}, 196 \mathrm{Hv}$ and $199 \mathrm{Hv}$ for the table traverse speeds of $40 \mathrm{~mm} / \mathrm{min}, 50 \mathrm{~mm} / \mathrm{min}$ and $60 \mathrm{~mm} / \mathrm{min}$ respectively. The tensile strength of dissimilar brass/steel joint was found to be lower than that of parent metals. The defect free brass/steel interfaces were seen by Scanning Electron Microscopy. It was illustrated that the stirred zone exposed to two main structures namely, recrystallized grains of brass and intercalated swirl and vortex-like structure which can be characterized both the recrystallized brass grains and steel layers. This work is one of the preliminary studies on the detailed examinations of the dissimilar brass/steel joined by Friction stir welding.
\end{abstract}

Keywords: Brass plates, Friction Stir Welding, Microstructure, Micro hardness, Steel plates.

\section{Introduction}

Welding process in plants is increasing rapidly and it came into existence as a viable manufacturing process. In fusion welding heat affected zone is wider and results in numerous defects. Plasma arc and laser beam welding are developed for sound welds with narrow heat affected zone. But these techniques are not suitable for reactive elements such as aluminium and magnesium. Brasses are used in engineering materials because of its high strength and corrosion resistance. But it is difficult to fusion weld of brass. Moreover it loses its physical and chemical properties which it normally possessed. It seems that friction stir welding will solve these problems and hence it needs experimental investigation in this subject. Even though there are so many researches in the literature about friction stir welding in aluminum and its alloys, researches about copper and its alloys especially brass are limited. Friction stir welding as a green technology and a solid state welding method can be used to join brass to steel.

Friction stir welding (FSW) is a solid-state joining technique in which coalescence occurs owing to thermo mechanical deformation of work pieces as the resulting temperature exceeds the solidus temperature of work piece. Owing to frictional heat between tool and work piece, material around the pin is softened and a solid state joint is produced without melting.

[1] Thomas et al. probably the first one to check out the feasibility of FSW of steel. They carried out FSW technique on $12 \%$ chromium alloy and low carbon steel in a modified vertical milling machine to test the bending and tensile strength of joint. [2] Reynolds et al. attempted FSW for 304L and experiments are carried out at constant feed rate and two different rotational speeds. It is evident that grain size of joint is less than that of base metal and existence of narrowband grain in stir zone for both rotational speeds. It is obvious that a joint with superior ductility than fusion welding is obtained.

[3] Lee and Jung et al. carried out research on FSW of copper. The experiment is conducted on $4 \mathrm{~mm}$ thick copper plates with the help of steel tool. It is observed that the size of grain in the nugget zone is very fine and equiaxed as compared to base metal. It is obvious from the study that the strength obtained by FSW is higher than that of electron beam welding. [4] Khodaverdizadeh et al. analyzed the work hardening behavior of FSW joints of pure copper alloys. The experiments are conducted at two different rotational speeds and constant feed rate and vice versa and it are evident that both factors influence the mechanical and metallurgical properties of copper joint. The grain size in SZ and HAZ decreases with increasing rotational speed and decreases in welding speed. Owing to this hardening capacity increases and stain hardening exponent decreases.

[5]Cho et al. investigated the microstructure of friction stir welded stainless steel plates. Cho et al. observed that the hardness of nugget zone is higher because of presence of bainitic structure in nugget zone. [6] Lin et al. compared the properties of friction stir welded pure copperplates with TIG and it is observed that FSW of copper produced $13 \%$ more efficient weld than TIG. Fusion welding affects the microstructure of steel and losses their corrosion resistance and toughness properties. 


\section{Experimental Procedure:}

Plates of brass and austenitic stainless steel $(50 \mathrm{~mm} \times 100 \mathrm{~mm})$ were butt joined by FSW. The High Carbon High Chromium steel tool comprising a shoulder of $18 \mathrm{~mm}$ in diameter, and probe diameter of $6 \mathrm{~mm}$ with a probe length of $2.9 \mathrm{~mm}$, which is $0.1 \mathrm{~mm}$ shorter than the thickness from the backing plate used. The effect of welding parameters on the brass/steel dissimilar joint was studied with different welding speeds of 40,50 and 60 $\mathrm{mm} / \mathrm{min}$ and with the fixed rotational speed and axial force of $550 \mathrm{rpm}$ and $9 \mathrm{kN}$ respectively. The austenitic stainless steel is harder than brass, so it is kept on the advancing side. In advancing side more heat generation occurs and in retreating side usually low heat generation occurs.

The softer material brass is kept on the retreating side. The tool pin is plunged on the retreating side in the brass with zero offset from center of the work piece Friction Stir Welded plates are shown in the Fig. 1. Morphology of the joints was studied using scanning electron microscopy (SEM). The Vickers hardness profile measurements were conducted on the cross-section of the joints using a micro-hardness tester under a load of $0.1 \mathrm{~N}$ and a holding time of $15 \mathrm{~s}$. the tensile test is made by using the universal testing machine.

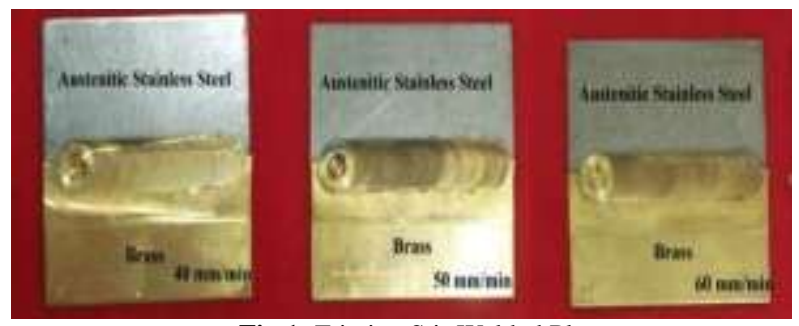

Fig 1: Friction Stir Welded Plates.

\section{Results and discussion:}

\subsection{Micro Hardness Survey}

As in Figure 2 it is clear that when the traverse speed is at 40 $\mathrm{mm} / \mathrm{min}$ the hardness value is found to be less. This is due to increased heat generation, because of the slow movement of the table. At $60 \mathrm{~mm} / \mathrm{min}$, improved hardness value is obtained in the heat affected zone which is due to reduction in heat input and increased table traverse speed. Also the intermetallic layers have not formed at traverse speed of $50 \mathrm{~mm} / \mathrm{min}$ and $60 \mathrm{~mm} / \mathrm{min}$. The average hardness obtained in the welds are $175 \mathrm{Hv}, 196 \mathrm{Hv}$ and $199 \mathrm{Hv}$ for table traverse speeds of $40 \mathrm{~mm} / \mathrm{min}, 50 \mathrm{~mm} / \mathrm{min}$ and $60 \mathrm{~mm} / \mathrm{min}$ respectively. During stirring, some portion of the steel from the advancing side flows to the retreating side and mixes with the brass. This is the reason for obtaining higher hardness values in the stir zone of the brass.

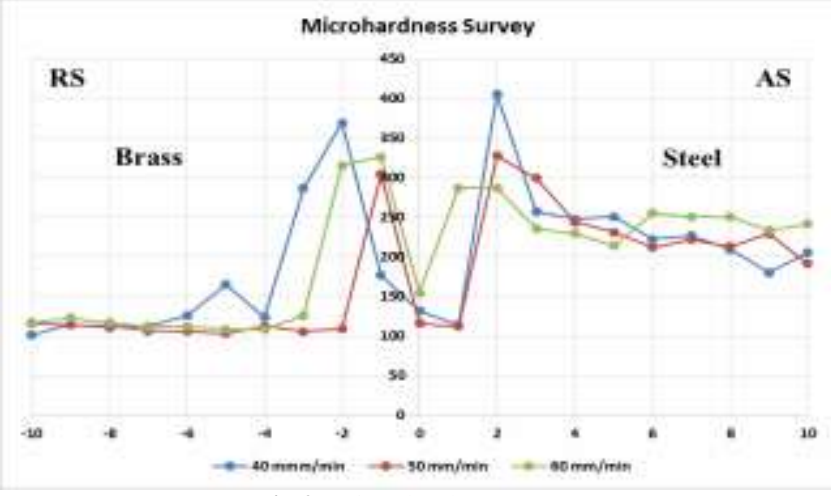

Fig 2: Micro hardness survey

\subsection{Intermetallic Layer Formation}

Fig. 3 shows the intermetallic layer formation with the average thickness of $4.09 \mu \mathrm{m}$. This layer was observed for the weld carried out at $40 \mathrm{~mm} / \mathrm{min}$. This intermetallic layer forms due to high heat input. Usually intermetallic will be highly brittle. This makes the weld zone very harder and it fails in the brittle mode.

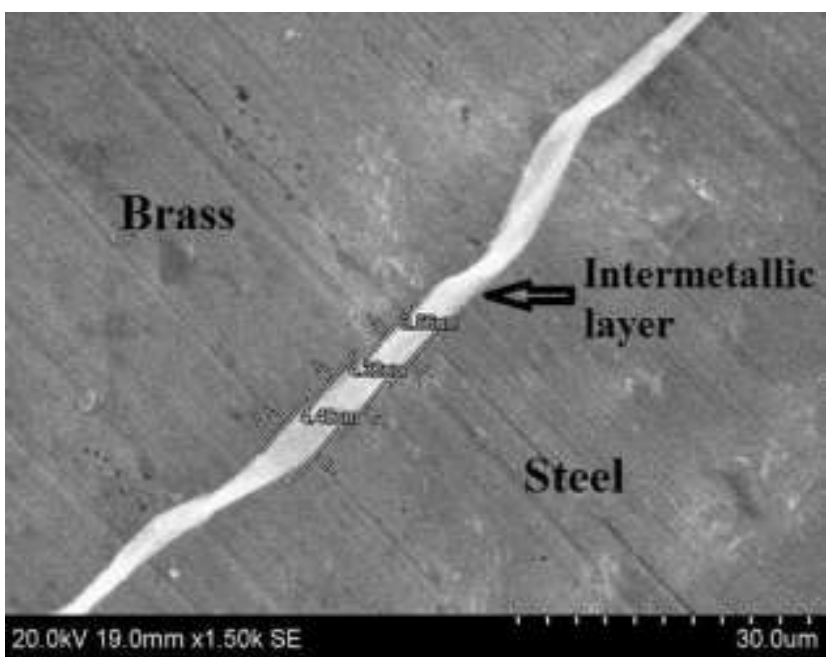

Fig 3: Intermetallic layer in interface at $550 \mathrm{rpm}$ and $40 \mathrm{~mm} / \mathrm{min}$.

\subsection{Tensile Test}

Figure 4 shows the tensile specimens before and after testing. Figure 5 illustrates the comparison of the stress-strain curves of the welded plates (brass/steel) used in the study.
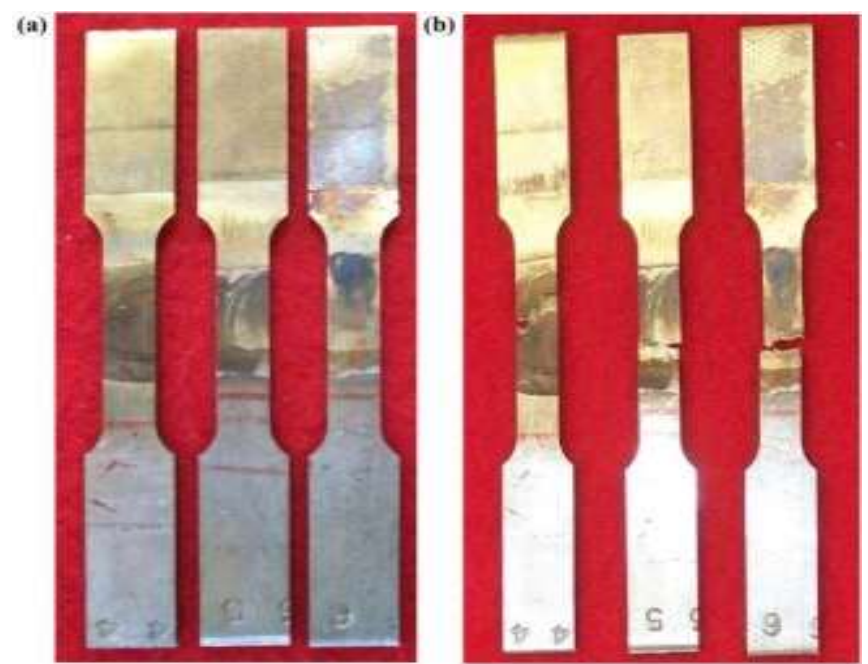

Fig 4: Tensile samples (a) Before and (b) After fracture
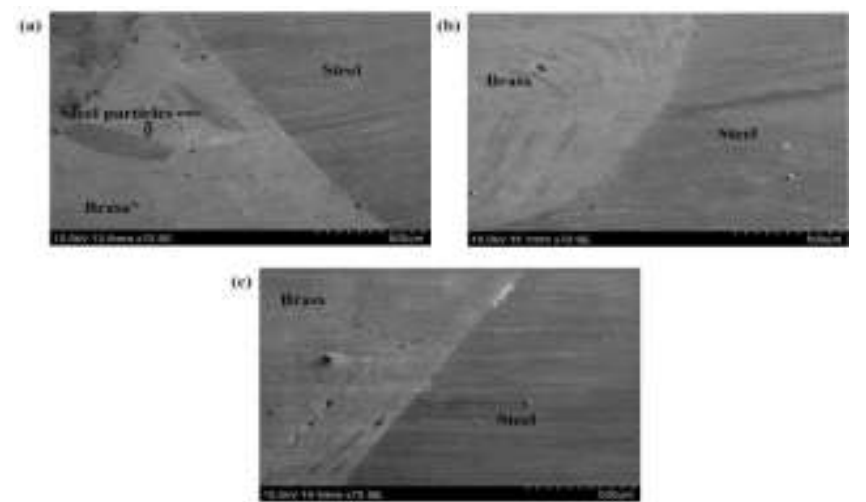

Fig 5: Ultimate tensile strength and Elongation 
The best combination of mechanical properties was obtained from the joint produced with a traverse speed of $60 \mathrm{~mm} / \mathrm{min}$ and at the tool rotational speed of $550 \mathrm{rpm}$. The fracture has not occurred in the stir zone for $60 \mathrm{~mm} / \mathrm{min}$. The specimens with a traverse speed of 40 and $50 \mathrm{~mm} / \mathrm{min}$ failed in the stirred zone. The ductility of the joint are lower for the joints fabricated at 40 and $50 \mathrm{~mm} / \mathrm{min}$ due to high heat input. The FSWed specimens fractured at the brass parent metal region (Advancing side) quite far from the weld center for the weld done at $60 \mathrm{~mm} / \mathrm{min}$. By using a slightly conical tool instead of cylindrical one, a combination of higher rotational and travel speeds can be employed for achieving sound joints. Figure 6 shows the SEM images at the weld joint interface.
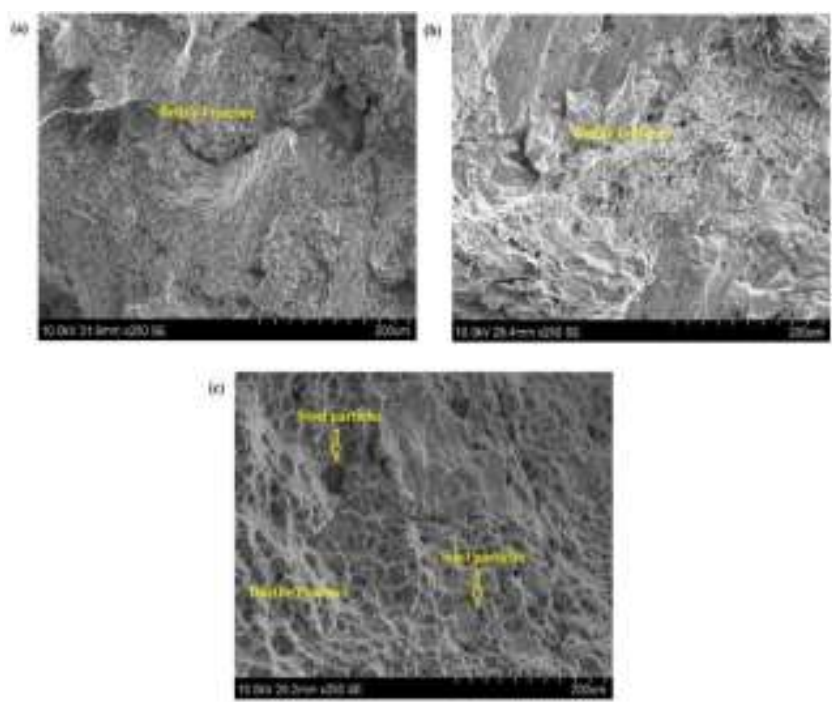

Fig 6: SEM images of weld interface at different traverse speeds.

\subsubsection{Tensile Fracture Surfaces}

At lower traverse speed more heat generation occurred, and formation of intermetallic layer at the interface of the brass/steel joints is seen. This intermetallic layer made the metal very brittle and the failure occurred by brittle mode. At the table traverse speed of $50 \mathrm{~mm} / \mathrm{min}$ in some portions of the SEM both ductile and brittle mode of failures occurred. Table speed of $60 \mathrm{~mm} / \mathrm{min}$ the heat generated is less and it is sufficient to bond the brass with steel and no intermetallic layer formation were observed and the mode of failure was ductile. Fig. 7 shows the tensile fractured surfaces at various traverse speeds.

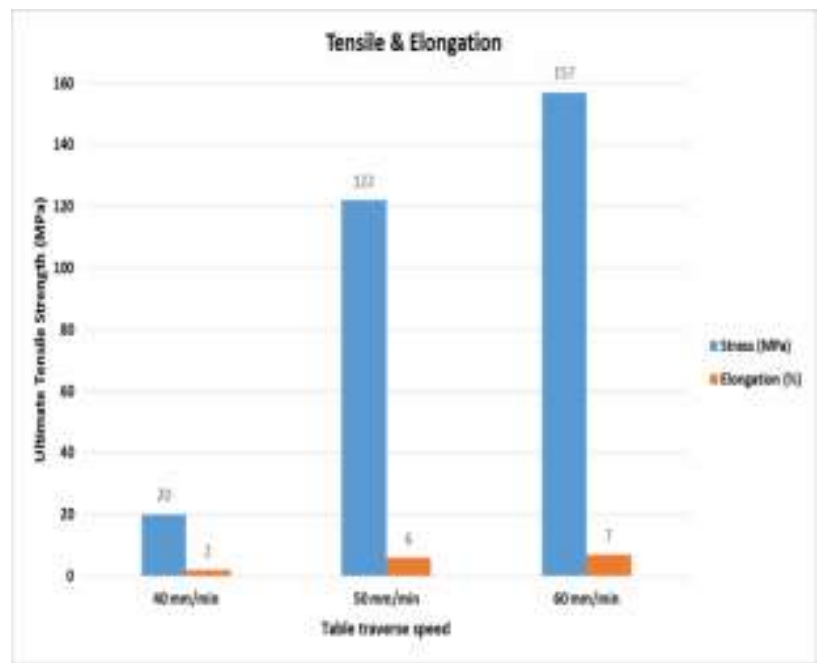

Fig 7: Tensile fractured surface at different traverse speeds.

\section{Conclusions}

The present study has demonstrated that brass can be successfully joined to steel by FSW. The average micro hardness obtained in the welds are $175 \mathrm{Hv}, 196 \mathrm{Hv}$ and $199 \mathrm{Hv}$ for table traverse speeds of $40 \mathrm{~mm} / \mathrm{min}, 50 \mathrm{~mm} / \mathrm{min}$ and $60 \mathrm{~mm} / \mathrm{min}$ respectively. Intermetallic layer made the metal very brittle and the failure occurred by brittle mode for the tables traverse speed of 40 $\mathrm{mm} / \mathrm{min}$. For the table traverse speed of $60 \mathrm{~mm} / \mathrm{min}$ the heat generated is less and it is sufficient to bond the brass with steel and no intermetallic layer formation were observed. The mode of failure obtained for $60 \mathrm{~mm} / \mathrm{min}$ was ductile.

\section{References}

[1] Thomas, W. M.; Threadgill, P. L. \& Nicholas, E. D. (1999). Feasibility of friction stir welding steel. J. of Material Processing Technology, 178, 342-349.

[2] Reynolds, A. P.; Tang, W.; Gnaupel-Herold, T. \& Prask, H. (2003). Structure, properties, and residual stress of 304L stainless steel friction stir welds. Scripta Materialia, 48, 1289-1294.

[3] Lee, W. \& Jung, S. B. (2004). The joint properties of copper by friction stir welding. Materials Letters, 58, 1041-1046.

[4] Khodaverdizadeh, H.; Mahmoudi, A.; Heidarzadeh, A. \& Nazari, E. (2012). Effect of friction stir welding (FSW) parameters on strain hardening behaviour of pure copper joints. Materials and Design, 35,330-334.

[5] Lin; W. J.; Chang, H. C. \& Wu, M. H. (2014). Comparison of mechanical properties of pure copper welded using friction stir welding and tungsten inert gas welding. J. of Manufacturing Processes, 16, 296-304.

[6] Sato, Y. S.; Yamanoi, H.; Kokawa, H. \& Furuhara, T. (2007) Microstructural evolution of ultrahigh carbon steel during friction stir welding. Scripta Materialia, 57, 557-560.

[7] Cho, H. H.; Kang, S. H.; Kim, S.H.; Oh, K. H.; Kim, H. J.; Chang, W. S. \& Han, H.N. (2012). Microstructural evolution in friction stir welding of high-strength line pipe steel. Materials \& Design, 34, 258-267. 